Document downloaded from:

http://hdl.handle.net/10251/116576

This paper must be cited as:

Medina Folgado, JR. (2001). Estimation of incident and reflected waves using simulated annealing. Journal of Waterway Port Coastal and Ocean Engineering. 213-221. doi:10.1061/(ASCE)0733-950X(2001)127:4(213)

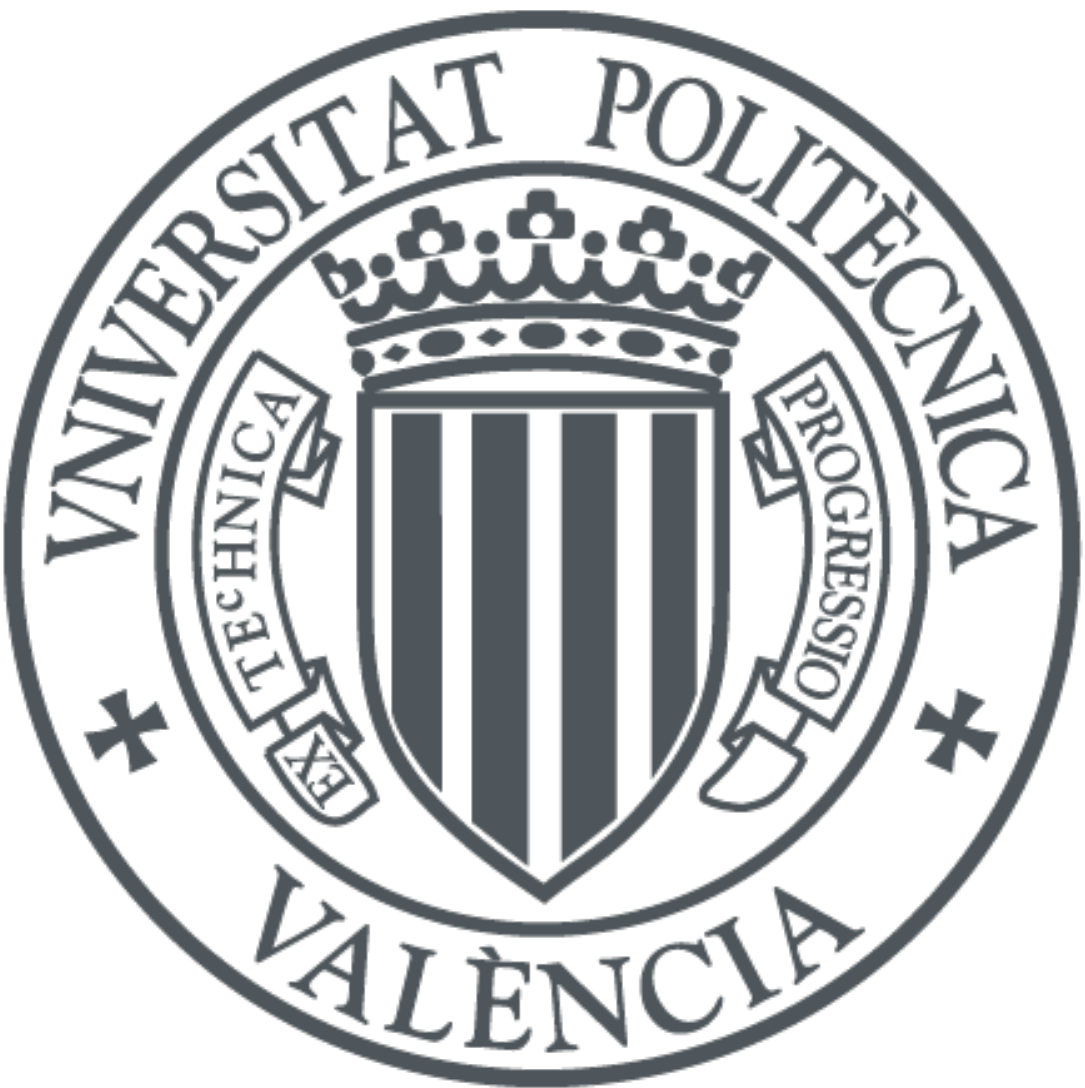

The final publication is available at

http://doi.org/10.1061/(ASCE)0733-950X(2001)127:4(213)

Copyright American Society of Civil Engineers

Additional Information 


\title{
Estimation of Incident and Reflected Waves Using Simulated Annealing
}

\author{
By Josep R. Medina, ${ }^{1}$ Member, ASCE
}

\section{INTRODUCTION}

The estimation of incident and reflected waves is a critical and difficult problem to be faced in a variety of laboratory and field experiments. The difficulty lies in the fact that the response of maritime structures depends on the incident wave field, but usually it is only possible to measure the incident added to the reflected wave field, which is part of the response of the structures. An adequate estimation of incident and reflected waves is then necessary for a precise modeling of the response of maritime structures.

Since the worldwide spread of irregular wave generation techniques for laboratory experiments began two decades ago, the multireflection problem and the estimation of incident and reflected waves have affected most experiments in wave flumes and basins; accordingly, a continuous research effort has been carried out to reduce the effects of re-reflected waves and to resolve the incident and reflected wave trains from measured records. Some authors have claimed to solve the multireflection problem in wave flumes using a variety of absorbing wavemakers (see Schäffer and Klopman, 2000); however, most of the wave absorption methods have not been published yet and some doubts still remain regarding the true effectiveness of methods 
${ }^{1}$ Professor, Dir. of the Lab. of Ports and Coasts, Dep. of Transportation, ETSI Caminos, Univ. Politécnica de Valencia, Camino de Vera s/n, 46022 Valencia, Spain.

based on sophisticated filters and black boxes. Therefore, the use of both the conventional and absorbing wavemakers in 2-D experiments usually demands a reliable method for discriminating the incident and the reflected wave trains in the wave flumes. The need for a reliable and robust method for estimating the incident and reflected wave fields from records is also evident in a variety of field experiments and 3-D tests in wave basins (Isaacson et al., 1996, Baquerizo et al., 1997, and Huntley et al., 1999); however, this paper focuses on the methods applicable to 2-D experiments in wave flumes, which usually provide the basic elements for more complex methods applied as well to 3-D experiments in field and wave basins.

Mansard and Funke(1987) analyzed in detail the estimation techniques employed by the nine laboratories of the IAHR Working Group on Wave Generation and Analysis. The 2-point method popularized by Goda and Suzuki(1976) and the 3-point least squares method of Mansard and Funke(1980) were the two basic methods used with different variants by each of the nine laboratories. The findings showed that the variants produced different estimations with the same input measurements. A variety of slightly different techniques based on the 2-point method popularized by Goda and Suzuki(1976), and extended to 3-point method by Mansard and Funke(1980) and Gailard et al.(1980) are presently used by many laboratories for a wide range of applications. The dispersion of techniques found by Mansard and Funke(1987) does not seem to have converged over the last decade; most 
laboratories seem to have a preferred specific technique which has been used in their own experiments over the past years.

The specific techniques are quite diverse, although the basic method used by most authors and laboratories is the classic 2-point method. The 2-point method is claimed to be used by Ward et al.(1996) at Texas A\&M University, Hughes(1992) at CERC, by An and Shibayama(1994) at Yokohama University, as well as by Capitao and Carvalho(1997) at LNEC, among others. Variants of the 2-point method have been proposed by different authors over the past two decades; one of the most widespread methods is the 3-point least squares method by Mansard and Funke(1980) which was used by Frigaard and Christensen(1994) to analyze the quality of an absorbing wavemaker. The 3-point least squares method was generalized by Zelt and Skjelbreia(1992) for an arbitrary number of wave gauges. The 3-point least squares method was used by Isaacson(1991) for introducing a method with two-dimensional wave gauge array in 3-D experiments which was used by Teisson and Benoit(1994) to introduce new directional methods for 3-D experiments in wave basins. Gronbech et al.(1996) proposed a modification of the method developed by Zelt and Skjelbreia(1992) for considering the cross modal activity of the wave flume.

In addition to the general purpose methods, a number of authors have proposed specific modifications of the 2-point and 3-point methods in order to fulfil the specific requirements of their research. Kimura(1985) proposed a modification of the 2-point method using time windows to study incident and reflected wave envelopes which may be applied to analyze nonstationary processes. Medina et al.(1994) used the modification proposed by Fassardi(1993), based on the 
phase-formulas given by Kimura(1985), to study the properties of the envelope of the incident wave trains. Kobayashi and Raichle(1994) used the modification given by Kobayashi et al.(1990) for separating incident and reflected waves with probes at different water depths. Recently, Klopman and Van der Meer(1999) have used the methods of Goda and Suzuki(1976), Zelt and Skjelbreia(1992) and a modification of the 3-point method of Mansard and Funke(1980) to analyze the reflectivity of coastal structures. Finally, Frigaard and Brorsen(1995) and Schäffer and Hyllested(1999) proposed to analyze incident and reflected waves using time-domain methods based on filters and control systems.

From the description of the wave-analysis techniques given above, it is evident that the 2-point method is the basis of most existing techniques for estimating incident and reflected waves in wave flumes and basins. Therefore, most existing techniques for estimating incident and reflected wave fields have the same shortcomings as the 2-point method: unstable at some specific frequencies, sensitive to noise, and inadequate for analyzing nonstationary and nonlinear processes. Some methods like the 3-point least squares method of Mansard and Funke(1980) may reduce the instability and sensitivity to noise, but stationarity and linearity still remain as two fundamental principles of the frequency-domain techniques used by most laboratories for separating incident and reflected waves. In this paper, an attempt is made to break through the barriers of stationarity and linearity introducing a new time-domain method based on local approximations optimized by simulated annealing (SA).

This paper first describes the classical 2-point method pointing out the explicit and implicit hypotheses of most frequency-domain techniques used for separating 
incident and reflected waves. Second, a local approximation method is proposed including classical linear waves and additional Stokes II nonlinear waves. Third, the SA optimization technique is described and used for estimating the best local approximations. Fourth, numerical experiments based on linear waves with and without white noise are used to compare three methods for separating incident and reflected waves: (1) the classical 2-point method, (2) the method proposed by Kimura(1985), and (3) the LASA (Local Approximation using Simulated Annealing) method proposed in this paper. Finally, physical experiments with nonstationary regular and irregular waves at the Universidad Politécnica de Valencia (UPV) wave flume are analyzed, as well as the corresponding estimations of incident and reflected waves using 2-point, Kimura's and LASA methods.

\section{2-POINT METHOD}

The 2-point method advanced by Kajima(1969) and Thornton and Calhoun(1972) and popularized by Goda and Suzuki(1976) is the basic method on which most existing techniques for separating incident and reflected waves in laboratory are founded. Appendix I describes the 2-point method given by Goda and Suzuki(1976) with additional formulae given by Kimura(1985) and Fassardi(1993) to take into consideration phase angles and wave envelopes. Further comments are given about the explicit and implicit assumptions of the 2-point method.

The 2-point method described in Appendix I has the following explicit and implicit hypotheses, assumptions and conditions:

(1) Linear Dispersion.- Linear dispersion relationship is strictly accomplished in the propagation process. 
(2) Stationary Waves.- Only regular wave components, with constant amplitude, phase and frequency are considered.

(3) Wave Superposition.- Linear superposition of waves is assumed when using DFT algorithms to calculate the wave components of irregular waves.

(4) Periodic Waves.- The wave records are assumed to be periodic. The period is N)t when using a DFT algorithm to calculate the wave components.

(5) Noise Free.- High and low frequency components as well as noise are assumed to be removed from the wave records.

(6) Global Estimation.- The complete wave record is necessary to estimate the incident and reflected wave trains. Therefore, the principle of causality is violated; past values of the incident waves estimated by the 2-point method are dependent on future values of the wave records.

The assumptions of the 2-point method described above are accomplished when using numerical simulations, but not when using real measurements in wave flumes. Hypothesis 2(stationarity), 3(wave superposition), and 4(periodicity) are similar to those required for typical spectral estimation, which usually requires an appropriate selection of time windows; therefore, the corresponding spectral smoothing has to be dealt with (see Kimura, 1985). In addition to the problem of typical spectral estimations, the 2-point method is based on additional assumptions related to the physics of wave propagation that imposes additional uncertainty on the results. Furthermore, the 2-point method is inadequate when nonlinearity or nonstationarity are significant aspects of the wave records, as one may expect in physical experiments. The method proposed by Kimura(1985), which is based on 
time windows, reduces the impact of hypothesis 2(stationarity), 4(periodicity) and 6(global estimation).

\section{LOCAL APPROXIMATION}

In order to avoid the shortcomings of the 2-point method, a fundamental change of the global approach by local approximation is proposed to define the new time-domain LASA method presented in this paper. According to Barker and Sobey(1996), local methods are used to seek an approximation to each small local segment of measured record instead of using them to seek a solution that matches the entire measured record. A method based on local approximations may then be applied to nonstationary wave fields, thereby avoiding some of the shortcomings associated with the 2-point method.

Kimura(1985) proposed a local approximation model based on the application of the formulae of the 2-point method using Gaussian time windows for separating incident and reflected envelopes. Appendix II describes the the Kimura's method used in this paper for comparative purposes. In this study, the classical 2-point method, the Kimura's method and the LASA method are compared in different scenarios. The 2-point method given by Goda and Suzuki(1976) is a global approach while the Kimura's method is a local approach; both methods are based on linear theory and frequency-domain analysis.

\section{APPENDIX III. REFERENCES}


An, N.N., and Shibayama, T.(1994). "Wave-current interaction with mud bed." Proc. 24th ICCE, ASCE, 2913-2927.

Ansari, N., and Hou, E.(1997). Computational intelligence for optimization. Kluwer Academic Publishers, Boston, USA.

Baquerizo, A., Losada, M.A., Smith, J.M., and Kobayashi, N.(1997). "Cross-shore variations of wave reflection from beaches." J. Wtrwy., Port, Coast., and Oc. Engrg., ASCE, 123(5), 274-279.

Barker, C.H., and Sobey, R.J.(1996). "Irregular wave kinematics from a pressure record." Proc., 25th ICCE, ASCE, 1034-1047.

Capitao, R., and Carvalho, M.M.(1997). "Separation of Incident and Reflected Spectra in Wave Flumes." Proc. Int. Conf. Coastal'97 - Computer Modelling of Seas and Coastal Regions III. Computational Mechanics Publications. 293-302.

Fassardi, C.(1993). Effects of Wave Groups on Breakwater Damage. Msc thesis, Oregon State University, Corvallis, Oregon.

Frigaard, P., and Brorsen, M.(1995). "A time-domain method for separating incident and reflected irregular waves." Coast. Engrg., 24, 202-215.

Frigaard, P., and Christensen, M.(1994). "An absorbing wave-maker based on digital filters." Proc., 24th ICCE, ASCE, 168-180.

Gailard, P., Gauthier, M., and Holly, F.(1980). "Method of analysis of random wave experiments with reflecting coastal structures." Proc., 17th ICCE, ASCE, 204-220.

Goda, Y., and Suzuki, Y.(1976). "Estimation of incident and reflected waves." Proc., 15th ICCE, ASCE, 828-845.

Gronbech, J., Jensen, T., and Andersen, H.(1996). “ Reflection analysis with separation of cross modes." Proc., 25th ICCE, ASCE, 968-980. 
Hughes, S.A. (1992). "Estimating wave-induced bottom velocities at vertical wall." J. Wtrwy., Port, Coast., and Oc. Engrg., ASCE, 118(2), 175-192.

Huntley, D.A., Simmonds, D., and Tatavarti, R.(1999). "Use of collocated sensors to measure coastal wave reflection." J. Wtrwy., Port, Coast., and Oc. Engrg., ASCE, 125(1), 46-52.

Isaacson, M.(1991). "Measurement of regular wave reflection." J. Wtrwy., Port, Coast., and Oc. Engrg., ASCE, 117(6), 553-569.

Isaacson, M., Papps, D., and Mansard, E.P.D.(1996). "Oblique reflection characteristics of rubble-mound structures." J. Wtrwy., Port, Coast., and Oc. Engrg., ASCE, 122(1), 1-7.

Kajima, R.(1969). "Estimation of incident wave spectrum in the sea area influenced by reflection." Coast. Engrg. In Japan, 12, 10-16.

Kimura, A.(1985). "The decomposition of incident and reflected random wave envelopes." Coastal Engineering in Japan, 28, 59-69.

Klopman, G., and Van der Meer(1999). "Random wave measurements in front of reflective structures." J. Wtrwy., Port, Coast., and Oc. Engrg., ASCE, 125(1), 39-45. Kobayashi, N., Cox, D.T., and Wurjanto, A.(1990). "Irregular wave reflection and run-up on rough impermeable slopes." J. Wtrwy., Port, Coast., and Oc. Engrg., ASCE, 116(6), 708-726.

Kobayashi, N., and Raichle, A.W.(1994). "Irregular wave overtopping of revetments in surf zones." J. Wtrwy., Port, Coast., and Oc. Engrg., ASCE, 120(1), 56-73. Laarhoven, P.J.M. van, and Aarts, E.H.L.(1987). Simulated Annealing: Theory and Applications. Kluwer Academic Publishers, Dordrecht, The Netherlands. 
Mansard, E.P.D., and Funke, E.R.(1980). "The measurement of incident and reflected spectra using a least squares method." Proc., 17th ICCE, ASCE, 154-172. Mansard, E.P.D., and Funke, E.R.(1987). "Wave measurement and analysis in laboratory flumes." Proc. IAHR Seminar on Wave Analysis and Generation in Laboratory Basins-XXII IAHR Congress, NRC of Canada, 75-152.

Medina, J.R., Aguilar, J., and Diez, J.J.(1985). "Distortions associated with random sea simulators." J. Wtrwy., Port, Coast., and Oc. Engrg., ASCE, 111(4), 603-628.

Medina, J.R., and Hudspeth, R.T.(1990). "A review of the analyses of ocean wave groups." Coast. Engrg., 14, 515-542.

Medina, J.R., Hudspeth, R.T., and Fassardi, C.(1994). "Breakwater armor damage due to wave groups." J. Wtrwy., Port, Coast., and Oc. Engrg., ASCE, 120(2), 179-198.

Schäffer, H.A., and Hyllested,P.(1999). "Reflection Analysis using an active wave absorption control system." Proc., Coastal Structures '99, A.A. Balkema, (Vol. 2):93-99.

Schäffer, H.A., and Klopman,G.(2000). "Review of multidirectional active wave absorption methods." J. Wtrwy., Port, Coast., and Oc. Engrg., ASCE, 126(2), 88-97. Teisson, C., and Benoit, M.(1994). "Laboratory measurement of oblique irregular wave reflection on rubble-mound breakwaters." Proc., 24th ICCE, ASCE, 1610-1623. Thornton, E.B., and Calhoun, R.J.(1972). "Spectral resolution of breakwater reflected waves." J. Wtrwy., Port, Coast., and Oc. Engrg., ASCE, 98(4), 443-460.

Ward, D.L., Zhang, J., Wibner, C.G., and Cinotto, C.M.(1996). "Wind effects on runup and overtopping." Proc., 25th ICCE, ASCE, 2206-2215. 
Zelt, J.A., and Skjelbreia, J.E.(1992). "Estimating incident and reflected wave fields using arbitrary number of wave gauges." Proc., 23rd ICCE, ASCE, 777-789.

\section{APPENDIX II. NOTATION}

The following symbols are used in this paper:

A = wave amplitude;

$\mathrm{AL}$ = wave amplitude of linear component;

$\mathrm{AN}=$ wave amplitude of nonlinear component;

$C_{A}, C_{B}=$ cost of solutions $A$, cost of solution $B$;

$\mathrm{Cr}=$ reflection coefficient;

$\mathrm{c}_{\mathrm{k}}=$ control parameter (temperature) of the simulated annealing algorithm;

$\mathrm{f}=$ frequency;

$\mathrm{f}_{\mathrm{p}}=$ peak frequency;

$\mathrm{g}$ = gravitational acceleration;

$\mathrm{h}=$ water depth;

$\operatorname{Im}[$.$] = imaginary part;$

$\mathrm{k}=2 \mathrm{~B} / \mathrm{L}=$ wave number;

$\mathrm{k}_{\max }=$ maximum number of Markov chains in the SA process;

$\mathrm{L}=$ wavelength;

LASA = Local Approximation using Simulated Annealing;

$\mathrm{L}_{\mathrm{M}}=$ length of the Markov chains in the SA process;

$\mathrm{l}=$ index of the Markov chain;

$\mathrm{M}_{2}, \mathrm{M}_{1}=$ highest and lowest frequency component;

$\mathrm{m}=$ frequency index; 
$\mathrm{m}^{\prime}=\mathrm{n}(\mathrm{t} \mathrm{t} /($ () () = index used for overlapping two local approximations;

$\mathrm{N}=$ number of data points in the time series;

$\mathrm{n}=$ time index;

$\mathrm{p}=$ number of wave gauges placed along the wave flume;

$\mathrm{q}=$ probability of parameter change fixed by the operator in the generation mechanism;

Re[.] = real part;

$\mathrm{r}, \mathrm{rmse}=$ relative mean squared error of estimated incident or reflected waves;

$S_{z}(f)=$ variance spectrum of $z(t)$;

$\mathrm{T}=$ wave period;

$\mathrm{T}_{01}=\mathrm{m}_{0} / \mathrm{m}_{1}=$ mean orbital period;

$\mathrm{T}_{<}=$temporal spectral peakedness parameter;

$\mathrm{t}=$ time;

$\mathrm{u}=$ time parameter used in (42) to (46); and random variable uniformly distributed in the interval $U(0,1]$;

$\mathrm{W}_{0}(\mathrm{u})$ and $\mathrm{W}_{1}(\mathrm{u})=$ time windows defined in (42) and (46);

$\mathrm{w}()=$. white noise time series;

$\mathrm{x}=$ horizontal coordinate in the wave flume direction;

$\mathrm{z}=$ water surface elevation;

$\exists=$ parameter to control the relative weight of the errors in (21);

$\exists \%=$ parameter to control variance of noise to variance of signal in (18);

e $=$ magnitude of the parameter alteration given by (10);

)f = frequency interval;

)l = distance between wave gauges; 
t, ) t’ = time interval of time series;

) $=$ half the duration of the time window = time interval of local estimations;

$+()=$. expected value;

, = phase angle;

$:_{\mathrm{e}}=$ mean value of (De fixed by the operator and used in (10);

$\mathrm{A}(\mathrm{x})=$ rectangle function;

$\Phi()=$. standard deviation;

$\mathrm{T}=2 \mathrm{~B} / \mathrm{T}=$ angular frequency;

\section{Subscripts}

$\mathrm{i}=1,2, \ldots=$ number of wave gauge;

$\mathrm{j}=$ index;

I, Ie = incident waves, estimated incident waves;

$\mathrm{m}=$ index, $\mathrm{mth}$ wave component;

$\max , \min =$ maximum, minimum

$\mathrm{R}, \mathrm{Re}=$ reflected waves, estimated reflected waves; and

$\mathrm{u}=$ time index . 


\section{LIST OF FIGURES}

Figure 1. Comparison of 2-point, LASA and Kimura's Methods for Estimating (IN) Incident and (RE) Reflected Waves Using Linear Simulations of Narrow Band Spectrum with Noise.

Figure 2. Longitudinal Cross Section of the UPV Wave Flume (dimensions in $\mathrm{cm}$ ).

Figure 3. LASA Estimation of Incident, Reflected and Re-reflected Wave Trains Corresponding to Regular Wave Generation $(\mathrm{H}=15 \mathrm{~cm}, \mathrm{~T}=1.5 \mathrm{~s})$.

Figure 4. First 35 seconds of the Output of the LASA Method Analyzing JONSWAP((=1). 

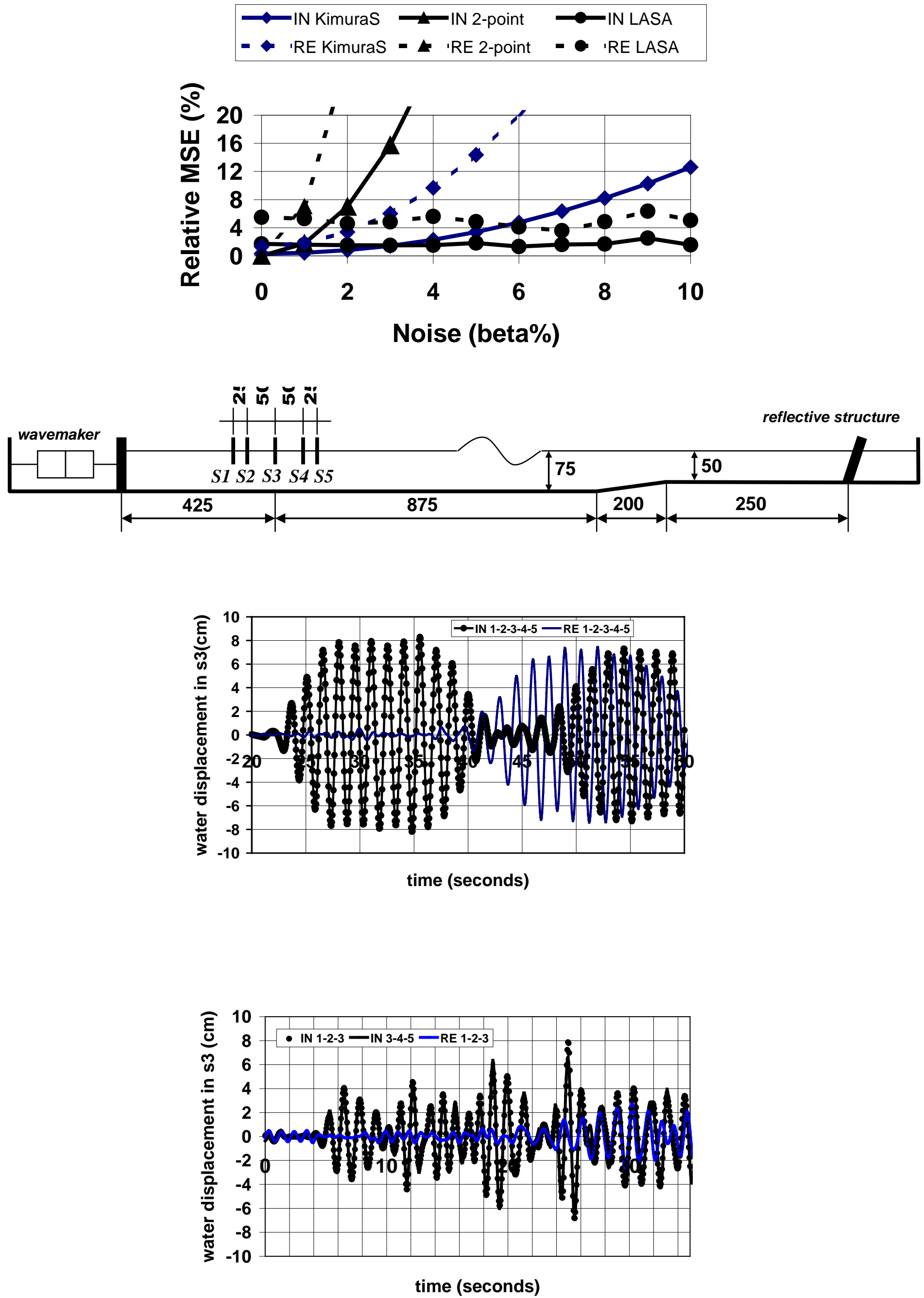